\title{
Critical Thinking in Respiratory Therapy
}

Critical thinking has been defined as the disciplined mental activity of evaluating arguments or propositions and making judgments that can guide the development of beliefs and action steps. ${ }^{1}$ There is little if any debate that graduate respiratory therapists (RTs) must have critical thinking skills in order to be successful in the current healthcare environment. These skills are crucial to RTs having the ability to define patient care issues with a high level of accuracy. ${ }^{2}$ Furthermore, RTs must have the ability to be objective and receptive to others' points of view with regard to patient care issues and be able to justify their own views based on data and logic. Critical thinking is also necessary as the RT evaluates evidence-based research in order to develop and evaluate care plans or recommend changes in respiratory therapy protocols. ${ }^{3}$ The ability to think critically is an essential component of providing quality respiratory care to patients.

A high level of critical thinking skills and the ability to apply the appropriate best-practice protocols have been identified as requisites for graduate RTs in 2015 and beyond. ${ }^{3}$ Critical thinking has become increasingly important as RTs work with more acutely ill patients, deal with sophisticated equipment and technology, face complicated ethical questions, and manage an ever growing body of knowledge. Accordingly, educators continue to search for strategies that enhance the level of practical clinical experience that is available to students, as well as the curricular content and critical thinking skills that will result in practitioners who are appropriately trained to meet the respiratory care needs of the population.

To foster critical thinking, educators must create learning environments that put emphasis on having the ability to: (1) pose clear and precise questions; (2) identify assumptions; (3) detect ambiguities; (4) use credible sources of information; (5) remain relevant to the issue; (6) look for viable alternatives; (7) withhold judgment; (8) deal with parts of a complex whole; (9) develop criteria for an answer; and (10) analyze arguments to come to appropriate conclusions. ${ }^{4}$ The educational environment must also place added value on creative problem-solving strategies rather than on simply knowing the "right" answers.

In this issue of the Journal, Wettstein et al present the findings of a single program's study of critical thinking ability in respiratory care students and its correlation with age, educational background, and performance on national board examinations. ${ }^{5}$ The study was well done and adds to the small body of literature on the factors that promote critical thinking in respiratory care students.

See the Original Study on Page 284

Wettstein et al found a significant positive association between a strong educational science course background and the critical thinking ability of senior respiratory care students, as measured with the Watson-Glaser Critical Thinking Appraisal short form (WGCTA-S). A strong science course background was defined as completion of $\geq 10$ credits in science courses in biology, chemistry, biochemistry, anatomy, physiology, physics, and/or microbiology. No significant relationship was found between WGCTA-S score and age, or WGCTA-S score and scores for the clinical simulation component of the National Board for Respiratory Care examinations.

The findings of the Wettstein et al study are interesting, but the generalizability of the findings to other respiratory care programs is limited by the study's small sample size, that was comprised of subjects from one educational program at the baccalaureate level. However, assessment of critical thinking ability might be useful as one of many criteria for admission selection, if and when a larger pool of qualified candidates from more than one institution is studied. Other criteria that may be evaluated in students on admission might include basic competencies such as communication skills, ability for self-reflection, problem-solving skills, ethics, and professionalism. ${ }^{6}$ In the interim it would stand to reason that selecting candidates with a stronger educational background, not only in the sciences but also the arts and humanities, will enable educators to increase the academic rigor of their programs and improve the credentialing success of graduates. Moreover, selection of appropriate candidates for admission will be more likely to result in a pool of graduate RTs needed to begin RT practice with the excellent critical thinking skills required to assimilate the complex technology and protocols of the future.

It also stands to reason that the ability to think critically may develop over time and with practice and/or encouragement from the learning environment. Thus, longitudinal studies are needed to quantify the critical thinking skills of students from program entry to exit, and perhaps one and 5 years after entry into practice. While one might 
assume that improving critical thinking will enhance competence, there is no evidence to prove or disprove that assumption. Thus, there is a need for studies with rigorous designs that will allow respiratory care educators to evaluate the effect of different teaching and learning strategies to cultivate critical thinking and problem-solving skills of RT students. Future studies are also needed to answer the following questions with regard to critical thinking. Does critical thinking alter RTs' clinical behavior? Does critical thinking improve patient care?

In my opinion, RTs who think critically will be more apt to search for answers to patient care issues and identify alternate solutions to problems. I believe that critical thinking is central to excellence in respiratory care education, practice, and research.

The author has disclosed no conflicts of interest.

Correspondence: Kathy Jones-Boggs Rye EdD RRT, Department of Respiratory and Surgical Technologies, College of Health Related Professions, University of Arkansas for Medical Sciences, 4301 W Markham Street, Slot 737, Little Rock AR 72205-7199. E-mail: ryekathyj@uams.edu.

DOI: $10.4187 /$ respcare.01245
Kathy Jones-Boggs Rye EdD RRT

Department of Respiratory and Surgical Technologies College of Health Related Professions University of Arkansas for Medical Sciences

Little Rock, Arkansas

\section{REFERENCES}

1. Huitt W. Critical thinking: an overview. Educational Psychology Interactive 1998. Valdosta, Georgia: Valdosta State University.

2. Shelledy DC, Gardner DD, Carpenter ME, Murphy DL. The relationship between general critical thinking ability and student performance. Respir Care Educ Annu 2004;13(Suppl):23-28.

3. Barnes TE, Gale DD, Kacmarek RM, Kageler WV. Competencies needed by graduate respiratory therapists in 2015 and beyond. Respir Care 2010;55(5):601-616.

4. Jones J. Teaching clientele what or how to think. Journal of Extension 1992;30(1). http://www.joe.org/joe/1992spring/a2.php. Accessed January 13, 2011.

5. Wettstein RB, Wilkins RL, Gardner DD, Restrepo RD. Criticalthinking ability in respiratory care students and its correlation with age, educational background, and performance on national board examinations. Respir Care 2011;56(3):284-289.

6. Mouradian W, Huebner C. The future of maternal and child health leadership. MCH Working Conference. Seattle, Washington: April 19-20, 2004. http://depts.washington.edu/mchprog/leadershipconf. Accessed January 13, 2011. 